\title{
Protective environment in hematopoietic cell transplantation centers: results of a survey of the Polish Federation of Bone Marrow Transplant Centers
}

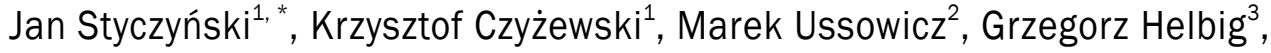 \\ Małgorzata Sobczyk-Kruszelnicka ${ }^{4}$, Anna Łojko ${ }^{5}$, Anna Czyż ${ }^{6}$, Beata Piątkowska-Jakubas ${ }^{7}$, \\ Agnieszka Sobkowiak-Sobierajska ${ }^{8}$, Agnieszka Zaucha-Prażmo ${ }^{9}$, \\ Aleksandra Krasowska-Kwiecieñ ${ }^{10,11}$, Kazimierz Hałaburda ${ }^{12}$, Piotr Boguradzki ${ }^{13}$, \\ Maria Bieniaszewska ${ }^{14}$, Agnieszka Wierzbowska ${ }^{15}$, Piotr Rzepecki ${ }^{16}$, Adam Walter-Croneck ${ }^{17}$, \\ Mariola Sędzimirska ${ }^{18}$, Agnieszka Druzd-Sitek ${ }^{19}$, Dorota Hawrylecka ${ }^{20}$, Bartłomiej Baumert ${ }^{21}$, \\ Ewa Lutwin ${ }^{22}$, Edyta Cichocka ${ }^{23}$, Katarzyna Smalisz ${ }^{24}$, Lidia Gil ${ }^{5}$
}

${ }^{1}$ Department of Pediatric Hematology and Oncology, Collegium Medicum, Nicolaus Copernicus University Toruń, Bydgoszcz, Poland ${ }^{2}$ Department of Pediatric Bone Marrow Transplantation, Oncology and Hematology, Wrocław Medical University, Wrocław, Poland

${ }^{3}$ Department of Hematology and Bone Marrow Transplantation, Medical School of Silesia, Silesian Medical University, Katowice, Poland

${ }^{4}$ Departament of Bone Marrow Transplantation and Oncohematology, Maria Skłodowska-Curie National Research Institute of Oncology - Gliwice Branch, Gliwice, Poland

${ }^{5}$ Department of Hematology, Poznań University of Medical Sciences, Poznań, Poland

${ }^{6}$ Department of Hematology, Blood Neoplasms and Bone Marrow Transplantation, Medical University, Wrocław, Poland

${ }^{7}$ Department of Hematology, Jagiellonian University Medical College, Kraków, Poland

${ }^{8}$ Department of Pediatric Hematology, Oncology and Transplantology, Medical University, Poznań, Poland

${ }^{9}$ Department of Pediatric Hematology, Oncology and Transplantology, Medical University, Lublin, Poland

${ }^{10}$ Department of Transplantation, Children's University Hospital, Kraków, Poland

${ }^{11}$ Department of Clinical Immunology and Transplantology, Jagiellonian University Medical College, Kraków, Poland

${ }^{12}$ Department of Hematology, Institute of Hematology and Transfusion Medicine, Warszawa, Poland

${ }^{13}$ Department of Hematology, Oncology and Internal Medicine, Medical University, Warszawa, Poland

${ }^{14}$ Department of Hematology, Medical University, Gdańsk, Poland

${ }^{15}$ Department of Hematology, Medical University, Łódź, Poland

${ }^{16}$ Department of Hematology, Military Institute of Medicine, Warszawa, Poland

${ }^{17}$ Department of Hematooncology and Bone Marrow Transplantation, Medical University, Lublin, Poland

${ }^{18}$ Lower Silesian Center for Cellular Transplantation and National Bone Marrow Donor Registry, Wrocław, Poland

${ }^{19}$ Department of Lymphoid Malignancies, Maria Skłodowska-Curie National Research Institute of Oncology, Warszawa, Poland

${ }^{20}$ Departament of Oncological Hematology and Transplantology, Podkarpacie Oncological Center, Brzozów, Poland

${ }^{21}$ Department of Hematology and Transplantology, Medical University, Szczecin, Poland

${ }^{22}$ Department of Hematology and Transplantology, Center of Oncology, Kielce, Poland

${ }^{23}$ Department of Hematology, Nicolaus Copernicus Town Hospital, Torun, Poland

${ }^{24}$ Department of Pediatric Hematology and Oncology and Clinical Transplantology, Medical University, Warszawa, Poland

\footnotetext{
*Address for correspondence: Jan Styczynski, Department of Pediatric Hematology and Oncology, Collegium Medicum, Nicolaus Copernicus University, Skłodowskiej-Curie 9, 85-094 Bydgoszcz, Poland, phone: +485258548 60, fax: +48 5258540 87, e-mail: jstyczynski@cm.umk.pl

PTHiT Copyright $\odot 2021$ The Polish Society of Haematologists and Transfusiologists, Insitute of Haematology and Transfusion Medicine. All rights reserved.
} 


\section{Introduction}

Hematopoietic cell transplantation (HCT) is one of the most immunosuppressive treatments performed currently in medicine. High level of protective environment is required for patients undergoing HCT to ensure safety of this treatment in the transplant setting. International guidelines on transplant protective environment for health-care facilities regarding hospital room design and ventilation were proposed as a set of 10 Global Recommendations on Protective Environment (GRPE) in 2009 [1, 2]. These guidelines were coordinated by the Center for International Blood and Marrow Transplant Research (CIBMTR), with the participation of the National Marrow Donor Program (NMDP), the American Society for Blood and Marrow Transplantation (ASBMT), the European Society for Blood and Marrow Transplantation (EBMT), the Infectious Diseases Society of America (IDSA), the Canadian Blood and Marrow Transplant Group (CBMTG), the Centers for Disease Control (CDC), the Association of Medical Microbiology and Infectious Disease (AMMI), and the Society for Healthcare Epidemiology of America (SHEA).

The objective of this study was to determine the current status on protective environment for HCT recipients in Polish transplant centers and to report current practices in the hospital transplant setting, with focus on room design and ventilation, as well as their agreement with GRPE recommendations.

\section{Methods}

\section{Study design}

During the Transplant Workshop of the Polish Federation of Bone Marrow Transplant Centers in Poznań, on October 12, 2019 , a survey on antimicrobial prophylaxis and protective transplant environment was carried out, with one questionnaire administered per transplant center. The part of the survey on protective environment was based on the GRPE recommendations $[1,2]$ and was compared with the results obtained from the survey of EBMT centers, performed in 2012 [3]. Results of the first part of the survey on antimicrobial prophylaxis have been analyzed elsewhere [4].

\section{Definitions}

High efficiency particulate air (HEPA) filter - a high-efficiency particulate air filter, with $99.97 \%$ efficiency in removing particles $\geq 0.3 \mu \mathrm{m}$ in diameter with safe ventilation of $\geq 12$ air exchanges/hour. A laminar air flow room - a room containing HEPA-filtered air that moves in a parallel unidirectional flow, such that the air enters the room from one side and exits this room from the other side. Combined room - a room designed for patients for isolation in order to protect them against airborne infections and provide specific protective environment by means of positive air pressure and laminar air flow [3].

\section{Bioethical issues}

No Bioethical Committee consent was necessary for this study, as no study was performed on patients; all participants of the survey are coauthors of this manuscript and give their agreement for publication.

\section{Statistical analysis}

Categorical variables were compared with the chi-square test. Odds ratio (OR) and confidence intervals (95\% Cls) were calculated for the difference in the rates of positive responses between this survey and the EBMT survey [3]. All reported $p$-values are two-sided; $p<0.05$ was considered statistically significant.

\section{Results and discussion}

\section{Center participation}

All 23 Polish HCT centers participated in the survey, including six pediatric and 17 adult centers. The summary of responses provided by the centers, in comparison to the positive responses of the EBMT centers, is shown in Table I.

\section{HEPA filters}

Central or point-of-use HEPA filters with $99.97 \%$ efficiency for removing particles $\geq 0.3 \mu \mathrm{m}$ in diameter ensuring safe ventilation of $\geq 12$ air exchanges/hour is a standard of care in all Polish centers, both for allo-HCT and auto-HCT, including centers that perform auto-HCT only. All but one center have air-conditioning systems (ACs) exclusively designed for the transplant unit, and in the case of the single nonconforming center, the AC is shared with the hospital pharmacy. The majority $(78 \%)$ of the centers declare regular replacement of HEPA filters, with variable frequency, but at least once a year. This regularity is higher than those reported by the EBMT centers (odds ratio $[\mathrm{OR}]=3.8 ; 95 \% \mathrm{Cl}=1.3-11.0 ; p=0.018$ ) [3]. Moreover, the majority of centers have a written procedure for filter maintenance and removal. GRPE recommendations require that filters should be replaced regularly based on manufacturers' recommendations, and, when there is ongoing construction, filtration efficiency should be monitored frequently to best determine the appropriate time for replacement $[1-3,5]$.

\section{Positive air pressure}

Consistent positive air pressure differential between the patient's room and the hallway of $\geq 2.5 \mathrm{~Pa}$ is required. Only $34 \%$ of centers are equipped with a permanently installed device or mechanism to constantly monitor the differential air pressure between the room and the corridor, and even fewer centers are capable of monitoring the air pressure in the anteroom, in addition to the air pressure in the patient's room. This rate is, however, exactly the same as in the EBMT survey [3]. Additionally, in $56 \%$ of centers, the 
Table I. Overall positive results of the survey with respect to global recommendations on Protective Environment (GRPE)

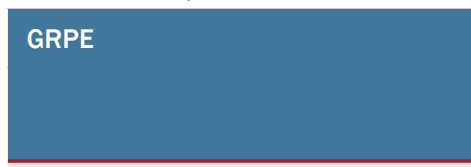

1. Ventilation: $\geq 12$ air changes per hour

2. Central or point-of-use HEPA filters with $99.97 \%$ efficiency for removing particles $\leq 0.3 \mu \mathrm{m}$ in diameter

3. Filters should be replaced regularly based on manufacturers' recommendations, and, when there is ongoing construction, filtration efficiency should be monitored frequently to best determine the appropriate time for replacement

4. Directed airflow so that air intake occurs at one side of the room and air exhaust occurs at the opposite side

5. Consistent positive air pressure differential between the patient's room and the hallway of $\geq 2.5 \mathrm{~Pa}$

6. Well-sealed rooms (e.g., filling the gaps between walls and windows, outlets, floor, and ceiling) should always be used for HCT patients to prevent infiltration of air from outside the room, which could allow entry of spores and hinder maintenance of proper pressure differential

7. Continuous pressure monitoring, especially while rooms are occupied

\section{Self-closing doors to maintain} constant pressure differentials

9. Monitoring systems that will set off an alarm when the pressure differential between any protective environment room and adjacent hallway or anteroom falls to $<2.5 \mathrm{~Pa}$, to alert staff to possible engineering failures

10. To enable the nursing staff to observe the HCT recipient even when the doors are closed, windows can be installed in either the door or the wall of the HCT recipient's room

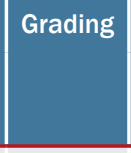

Alll

Alll Are your patient rooms equipped

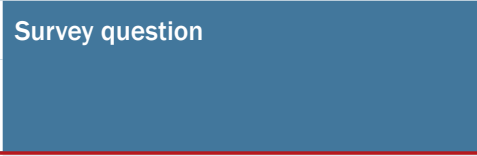

Does the room have at least 12 air changes per hour? with HEPA filters?

All How often are the filters changed? (Response: regularly, at least once per year)

Do you have a written procedure for filter maintenance and removal?

Is a sensor monitor installed in the patient room, which is used to determine when the HEPA filters require changing?

BIII Is the airflow directed so that air intake occurs at one side of the room, while the air exhaust occurs at the opposite side?

Is there a permanently installed devi-

BII ce/mechanism to constantly monitor the differential air pressure between the room and the corridor?

BIII Are the room windows sealed to eliminate infiltration from outside?

Do the protective environment rooms have monolithic ceilings?

Are all plumbing pipes in the room sealed around wall penetrations?

Is there an air pressure-monitoring device/mechanism in the anteroom, in addition to the air pressure in the patient's room?

BIII Are there self-closing doors to maintain constant pressure differentials?

CIII Is there a monitoring system that will set off an alarm when the pressure differential between any protective environment room and adjacent hallway or anteroom falls to $<2.5 \mathrm{~Pa}$, to alert staff to possible engineering failures?

CIII Is the nursing staff able to observe the patient even when the doors are closed?

\section{\begin{tabular}{|c|c|}
\hline \multicolumn{2}{|c|}{ Positive response } \\
\hline $\begin{array}{c}\text { Poland, 2019 } \\
(n=23)\end{array}$ & $\begin{array}{c}\text { EBMT, 2012 } \\
\left(n=177^{*}\right)\end{array}$ \\
\hline
\end{tabular}}

$23(100 \%) \quad 126(71.2 \%)$

$23(100 \%) \quad 176(99.4 \%)$

ND

$18(78.3 \%)$

$52(48.6 \%)$

$\mathrm{OR}=3.8$, $p=0.018$

$15(65.2 \%)$

$95(53.7 \%) \quad O R=1.6$,

$p=0.41$

$8(34.8 \%)$

$32(18.1 \%)$

$\mathrm{OR}=2.4$,

$p=0.10$

$13(56.5 \%)$

105

$\mathrm{OR}=0.9$, $p=0.97$

$8(34.8 \%)$

$68(38.4 \%)$

$\mathrm{OR}=0.9$, $p=0.91$

$\mathrm{OR}=2.0$,

$p=0.33$

$12(52.2 \%)$

$62(35.0 \%)$

$\mathrm{OR}=2.0$,

$p=0.16$

12 (52.2\%)

91 (51.4\%)

$\mathrm{OR}=1.0$,

$p=0.94$

$5(21.7 \%)$

31 (17.5\%)

$\mathrm{OR}=1.3$,

$p=0.83$

10 (43.5\%)

$66(37.3 \%)$

$\mathrm{OR}=1.3$,

$p=0.72$

$3(13.6 \%)$

$60(33.9 \%)$

$\mathrm{OR}=0.3$,

$p=0.073$

17 (73.9\%)

109 (61.6\%)

$\mathrm{OR}=1.8$, $p=0.35$

*Not all centers responded to all questions; EBMT - European Society for Blood and Marrow Transplantation; OR - odds ratio; ND - not done; HEPA - high efficiency particulate air; HCT - hematopoietic cell transplantation 
airflow is directed such that air intake occurs at one side of the room, while the air exhaust occurs at the opposite side. However, only three (13.6\%) centers have a monitoring system that sets off an alarm, especially while rooms are occupied, when the pressure differential between any protective environment room and the adjacent hallway or anteroom falls to $<2.5 \mathrm{~Pa}$, in order to alert the staff to possible engineering failures. Nevertheless, these figures are also comparable to the results of the EBMT survey [3].

\section{Well-sealed rooms}

Rooms having monolithic ceilings and well-sealed walls and floor should always be used for HCT patients to prevent infiltration of air from outside the room, which could allow entry of spores and hinder maintenance of proper pressure differential. This is also relevant for any plumbing pipes in the room and anteroom. More than half of the centers reported having these technological solutions, with the rate being comparable to the results of the EBMT survey [3].

\section{Self-closing doors}

In order to maintain constant pressure differentials, self-closing doors additionally can secure the protective environment. This is a routine in $43.5 \%$ Polish centers. In European centers, it is not more frequent [3].

\section{Observing HCT recipients}

In a vast majority of centers, the nursing staff is able to observe the HCT recipient even when the doors are closed. This is possible due to the presence of monitoring systems with cameras; in other centers, windows are installed in either the door or the wall of the HCT recipient's room.

\section{Clinical implications of results of the survey}

All Polish transplant centers together have created the Polish Federation of Bone Marrow Transplant Centers and actively cooperate at the organizational, medical, educational, and scientific levels. This survey shows that there are some differences in technological solutions among the centers. The differences might result from the different periods of establishment of transplant units: possibly, newer units are built more innovatively and equipped better than the older ones. It should be kept in mind that the survey was answered by physicians exclusively, without contact with supporting technical staff. It is highly probable that physicians and other health-care personnel of the transplant unit do not have access to the necessary information on technical issues in their own center. Nevertheless, all centers ensure proper isolation of the transplant patient, as well as proper room ventilation with the use of HEPA filters. The quality of medical service was additionally confirmed by the first accreditations for chimeric antigen receptor (CAR) T-cell therapy in several Polish transplant centers $[6,7]$.
The limitation of the study is the small number of transplant centers in Poland, disabling any further comparisons, e.g., pediatric vs adult centers. Furthermore, the survey was not aimed at any microbiological procedures ensuring protective environment. Nevertheless, regular microbiological screening for bacterial and fungal colonization should be performed inside the ward.

\section{Conclusion}

The results of this survey confirm that safe and protective patient isolation and protective environment are provided in all Polish transplant centers at the level that meets the required international standards.

\section{Authors' contributions}

JS, LG - design of the study and writing the manuscript. JS, $L G, A Ł, K C$ - performing the survey. All authors - critical review and final approval.

\section{Conflicts of interest}

All authors have no conflicts of interest to disclose with respect to this paper.

\section{Financial support \\ None.}

\section{Ethics}

The work described in this article has been carried out in accordance with The Code of Ethics of the World Medical Association (Declaration of Helsinki) for experiments involving humans; EU Directive 2010/63/EU for animal experiments; Uniform requirements for manuscripts submitted to biomedical journals.

\section{References}

1. Tomblyn M, Chiller T, Einsele H, et al. Center for International Blood and Marrow Research, National Marrow Donor program, European Blood and Marrow Transplant Group, American Society of Blood and Marrow Transplantation, Canadian Blood and Marrow Transplant Group, Infectious Diseases Society of America, Society for Healthcare Epidemiology of America, Association of Medical Microbiology and Infectious Disease Canada, Centers for Disease Control and Prevention. Guidelines for preventing infectious complications among hematopoietic cell transplantation recipients: a global perspective. Biol Blood Marrow Transplant. 2009; 15(10): 1143-1238, doi: 10.1016/j. bbmt.2009.06.019, indexed in Pubmed: 19747629.

2. Yokoe D, Casper C, Dubberke E, et al. Center for International Blood and Marrow Transplant Research, National Marrow Donor Program, European Blood and Marrow Transplant Group, American Society of Blood and Marrow Transplantation, Canadian Blood and Marrow Transplant Group, Infectious Disease Society of America, Society for Healthcare Epidemiology of America, Association of Medical Microbiology and Infectious Diseases Canada, Centers for Disease Control and 
Prevention. Infection prevention and control in health-care facilities in which hematopoietic cell transplant recipients are treated. Bone Marrow Transplant. 2009; 44(8): 495-507, doi: 10.1038/bmt.2009.261, indexed in Pubmed: 19861984.

3. Styczynski J, Tridello G, Donnelly JP, et al. Protective environment for hematopoietic cell transplant (HSCT) recipients: The Infectious Diseases Working Party EBMT analysis of global recommendations on health-care facilities. Bone Marrow Transplant. 2018; 53(9): 1131-1138, doi: 10.1038/s41409-018-0141-5, indexed in Pubmed: 29535381.

4. Styczyński J, Czyżewski K, Ussowicz M, et al. Antimicrobial prophylaxis in patients after hematopoietic cell transplantation: results of a survey of the Polish Federation of Bone Marrow Transplant Centers. Acta Haematol Pol. 2020; 51(3): 183-186, doi: 10.2478/ahp-2020-0032.

5. Hicheri $\mathrm{Y}$, Einsele $\mathrm{H}$, Martino R, et al. Environmental prevention of infection in stem cell transplant recipients: a survey of the Infectious Diseases Working Party of the European Group for Blood and Marrow Transplantation. Transpl Infect Dis. 2013; 15(3): 251-258, doi: 10.1111/tid.12064, indexed in Pubmed: 23465046.

6. Styczyński J. Where dreams come true: CAR-T cell therapy in Poland! Acta Haematol Pol. 2020; 51(1): 1, doi: 10.2478/ahp-2020-0001.

7. Dytfeld D, Łojko-Dankowska A, Matuszak M, et al. Road to clinical implementation of CAR-T technology in Poznań. Acta Haematol Pol. 2020; 51(1): 24-28, doi: 10.2478/ahp-2020-0006. 